\title{
APUNTES PARA UNA REFORMA DE LA REGULACIÓN LABORAL DE LA SUBCONTRATACIÓN DE OBRAS Y SERVICIOS
}

\author{
Notes for the outsourcing regulation reform \\ Rafael Gómez Gordillo*I \\ Universidad Pablo de Olavide, España
}

\begin{abstract}
RESUMEN
La reforma de la normativa laboral que regula el fenómeno de la subcontratación o externalización productiva es una de las prioridades de Gobierno y Sindicatos en el presente ciclo de reformas. La actividad de las empresas multiservicios ha permitido evidenciar la necesidad de acometer una reforma integral de una regulación que ha permanecido bastante estable desde la aprobación de la versión original del Estatuto de los Trabajadores. La propuesta de reforma más conocida plantea la igualación de las condiciones de trabajo de empresa principal y contratista, aunque en sede parlamentaria ha sido plateada la conveniencia de extender la acción normativa sobre algunos otros aspectos de la regulación. El artículo estudia las propuestas realizadas por los distintos grupos parlamentarios y reflexiona sobre otros aspectos que, en opinión del autor, debieran ser objeto de consideración.
\end{abstract}

Palabras clave: subcontratación, descentralización, externalización productiva, propia actividad, reforma laboral.

\section{ABSTRACT}

The outsourcing labour regulation reform is one of Government and Trade Unions priorities in the current cycle of reforms. The multi-service companies have made it possible to demonstrate the need to undertake an in-depth reform of a regulation that has remained fairly stable since the original version of the Labour Code. The most wellknown reform proposal focuses on the equalization of the working conditions of the main and auxiliary companies, but parliament it has also been proposed to extend normative action on some other aspects of regulation. The paper studies the proposals made by different parliamentary groups and presents some lines of reforms that, in the author's opinion, should be considered.

Keywords: outsourcing, main activity, labour reform.

${ }^{1}$ Este trabajo ha sido realizado en el marco del proyecto de investigación: «Los Derechos Fundamentales ante las Transformaciones Laborales en la Nueva Economía (DER2017-83488-C4-1R)».

* Correspondencia a: Rafael Gómez Gordillo. Carretera de Utrera, km 1, Sevilla, España. — rgomgor@upo.es — https: //orcid. org/0000-0002-8149-8503

Cómo citar: Gómez Gordillo, Rafael. (2021). «Apuntes para una reforma de la regulación laboral de la subcontratación de obras y servicios"; Lan Harremanak, 45, 110-137. (https: //doi.org/10.1387/lan-harremanak.22813).

Recibido: 15 mayo, 2021; aceptado: 07 junio, 2021.

ISSN 1575-7048 - elSSN 2444-5819 / (C) 2020 UPV/EHU

(c) (i) Esta obra está bajo una licencia

Creative Commons Atribución 4.0 Internacional 


\section{Los cambios en la organización productiva y sus efectos sobre la eficacia de la regulación vigente}

La descentralización de las organizaciones de producción de bienes o prestación de servicios afecta en la actualidad a todos los sectores de la actividad, muy lejos del panorama empresarial que en los ańos setenta vio nacer la regulación laboral sobre contratas. En este contexto, la aparición de las empresas multiservicios ha servido para evidenciar con mayor nitidez las carencias normativas, que han provocado el fracaso del ordenamiento laboral espańol en el objetivo de garantizar condiciones de trabajo dignas para quienes prestan servicio en actividades contratadas o subcontratadas. Las primeras versiones de la regulación en la materia apuntaban hacia otras amenazas y, por ello, se centraban en establecer mecanismos de garantía de los créditos laborales, aunque conviene recordar que las reformas operadas en el presente siglo sobre el art. 42 del Real Decreto Legislativo 2/2015, de 23 de octubre por el que se aprueba el Estatuto de los trabajadores, BOE de 24 de octubre (en adelante, ET), mostraban ya la preocupación por el deterioro de las condiciones de trabajo de las personas trabajadoras involucradas en relaciones jurídicas de alcance triangular. En concreto, la exposición de motivos de la Ley 12/2001, de 9 de julio, de medidas urgentes de reforma del mercado de trabajo para el incremento del empleo y la mejora de su calidad (BOE de 10 de julio), modificaba el art. 42 ET para «dotar a estas situaciones laborales de la debida transparencia y seguridad jurídica», mientras que la Ley 43/2006, de 29 de diciembre, para la mejora del crecimiento y del empleo (BOE de 30 de diciembre), volvía a alterar el texto del precepto con el fin de «asegurar que la organización empresarial de la producción mediante diversas fórmulas de descentralización productiva sea compatible con la protección de los trabajadores».

A pesar de ello, la laxitud del sistema de tutela legal ha permitido a las empresas multiservicios la puesta en marcha de un modelo de negocio que, sobre la base de la precarización de las condiciones de trabajo, ha registrado un notable y vertiginoso crecimiento. Es innegable que esta evolución se ha visto impulsada por avances tecnológicos y organizacionales, pero, sin duda, se ha apoyado también en un marco normativo favorable que, a las limitaciones originales, sumó los cambios operados en 2012 sobre la estructura de la negociación colectiva. Junto a otros elementos, la reforma del sistema de negociación colectiva introducidas vía Real Decreto-Ley 3/2012, de 10 de febrero, de medidas urgentes para la reforma del mercado laboral (BOE de 11 de febrero), concedió carta de naturaleza jurídica a la prioridad aplicativa del convenio de empresa, posibilidad que habilitaba a los negociadores en dicho ámbito para empeorar las condiciones de trabajo cardinales establecidas en el convenio colectivo sectorial (Gómez Gordillo, R., 2019). Junto a la aplicación prioritaria del convenio de empresa, la singular configuración de las empresas multiservi- 
cios puso en discusión el tradicional sistema de selección del convenio sectorial aplicable en las empresas sin convenio propio. Esta circunstancia debilitó la garantía proporcionada por el mecanismo sectorial autónomo de equiparación de las condiciones de trabajo por sectores de la actividad económica. En suma, las personas que prestan servicios por cuenta de empresas multiservicios quedan al margen tanto de los mecanismos específicos de garantía establecidos para las contratas, porque en la mayoría de los supuestos su actividad no es considerada propia actividad, como de los mecanismos generales de protección vinculados a la autonomía colectiva, en este segundo caso por aplicación de la prioridad aplicativa de los convenios de empresa o por la desorganización de las categorías sobre la que se estructura la negociación colectiva sectorial en nuestro país.

La jurisprudencia ha contribuido a limitar la celebración de convenios de empresa mediante la declaración de nulidad de los acordados por representaciones de los trabajadores que adolecen de falta de legitimación suficiente para negociar por ruptura del principio de correspondencia (STS n. ${ }^{\circ} 4001 / 2016$, de 14 de julio de 2016, rec. 219/2015). Por otra parte, en ausencia de convenios de ámbito empresarial, y con el objetivo de cerrar la puerta al uso torticero de las normas sobre estructura de la negociación colectiva, la jurisprudencia ha señalado como aplicable el convenio colectivo sectorial de la actividad efectivamente desempeñada por las personas que prestan servicio en el marco de la contrata

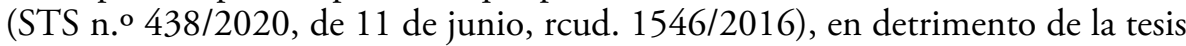
inicial que consideraba aplicable el convenio de la actividad preponderante (STS n. ${ }^{\circ}$ 1539/2015, de 17 de marzo, rcud. 1464/2014).

A pesar de lo dicho, la suma de elementos jurídicos y metajurídicos ha permitido a este tipo de empresas ocupar una posición central en un área de negocio que emerge con un protagonismo singular (Gómez Gordillo, R., 2018). El suministro de todo tipo de servicios a empresas, en particular, aquellos en los que el factor humano cobra una superior relevancia, permite a las empresas simplificar los mecanismos de ajuste de la mano de obra y reducir de manera capital los gastos de personal, bloqueando la acción de los mecanismos constitucionales de equilibrio o reparto del beneficio empresarial. El crecimiento de estas empresas se ha cimentado mediante un proceso de extensión transversal, que hoy día permite ofertar una gran tipología de servicios de apoyo a la actividad empresarial, añadiendo a las actividades más tradicionales otras de diversa naturaleza. La pléyade de servicios que suele englobar el objeto social de estas empresas siembra la duda sobre el argumento que defiende que su principal ventaja competitiva es la especialización productiva, recelo que se ve confirmado por el análisis del contenido de los convenios colectivos de empresa o centro de trabajo aplicables (VV.AA., 2018). En la práctica, estos convenios sirven al objetivo de mermar los estándares de condiciones de trabajo fijados en los convenios de ámbito sectorial. 
La descentralización productiva está provocando un proceso de centrifugación de las relaciones laborales que afecta gravemente la eficacia de la normativa laboral (Gómez Gordillo, R., 2010). El objetivo de reequilibrar las relaciones de trabajo en las contratas exige el diseño de un sistema de garantías que exceda el ámbito del aseguramiento de la satisfacción de las deudas salariales y de seguridad social para un número limitado de actividades. Los fines y funciones de la regulación deben ser redefinidos desde una perspectiva más realista, a partir de las experiencias negativas que caracterizan el final del siglo pasado y las primeras décadas del presente. El fenómeno de la descentralización productiva debe ser objeto de una regulación integral, que afronte el proceso de precarización de las condiciones de trabajo, la actividad de las representaciones de los trabajadores en la empresa, el ejercicio de las libertades sindicales, y el efecto útil de regulación en materia de negociación colectiva.

\section{Disfuncionalidad de la regulación laboral vigente}

La estructura del marco normativo laboral de la subcontratación de obras y servicios en nuestro país ha permanecido prácticamente invariada desde la primera versión del ET. La regulación original, con alcance muy similar al actual, circunscribía su objetivo al aseguramiento de la satisfacción de los créditos salariales y de seguridad social. Las líneas maestras del marco normativo ya estaban presentes con anterioridad a la aprobación del ET, si bien el grado de protección resultaba algo más intenso. En concreto, la genérica responsabilidad respecto de «las obligaciones contraídas por los subcontratistas con sus trabajadores», quedó reducida a las obligaciones de naturaleza salarial hasta «el límite de lo que correspondería si se hubiese tratado de su personal fijo en la misma categoría o puestos de trabajo», doble modificación que excluye las obligaciones de carácter extrasalarial y limita la cuantía de las de naturaleza salarial; por otro lado, se excluyen dos tipos de actividades del ámbito de responsabilidad del precepto, «la construcción o reparación» de la vivienda del empresario principal, y las contrataciones realizadas en el ámbito de actividades ajenas a la empresarial. La adición, ya en la primera década del siglo presente, de derechos de información para los trabajadores de la contratista (apdo. 3) y para sus representantes (apdo. 5), y de facultades de representación de los trabajadores de carácter subsidiario y limitado (apdo. 6) no altera en lo fundamental el propósito regulatorio (Soriano Cortés, D., 2000). Esta infrecuente estabilidad podría justificarse en la idoneidad del régimen jurídico, aunque, como se tratará de acreditar en los párrafos que siguen, no parece ser el caso del vigente art. $42 \mathrm{ET}$. El ańadido de aquellos cinco apartados no ha servido al objetivo de garantizar condiciones de trabajo dignas para las personas que prestan servicio en actividades externalizadas, particularmente 
precarizadas desde la aparición en escena de las empresas multiservicios (Esteve Segarra, M.A., 2017).

\subsection{Ausencia de sistematicidad y dudas interpretativas}

La regulación laboral que ordena la subcontratación adolece de falta de sistematicidad y genera dudas interpretativas. Los errores originales, el paso del tiempo y la falta de actualización han puesto de manifiesto la necesidad de una reforma que reordene el marco de referencia. En primer lugar, el art. 42 ET forma parte del capítulo III, que regula las fórmulas de modificación, suspensión y extinción del contrato y, más concretamente, de la sección segunda de dicho capítulo, que a su vez regula las garantías por cambio de empresario, junto a las reglas sobre cesión ilegal de trabajadores y transmisión de empresa. Entre estos preceptos, el art. 44 ET sería el único que hace mérito a las rúbricas del capítulo y de la sección. La subcontratación no supone una modificación subjetiva del contrato ni, por supuesto, su suspensión o su extinción. El contrato de la persona que presta servicios en una empresa contratista no es objeto de subrogación por la comitente, salvo que se produzca el fenómeno de la cesión ilegal de trabajadores prohibido por el art. $43 \mathrm{ET}$, y siempre que aquélla ejerza el derecho de opción previsto en el apdo. 4 de dicho precepto; también puede darse dicha circunstancia en supuestos de sucesión de contratas o cuando la empresa principal asume directamente la actividad anteriormente externalizada, ahora por aplicación del art. 44 ET. Pero lejos de estos supuestos, la subcontratación no está vinculada a ninguna modalidad de novación subjetiva del contrato de trabajo.

Por otra parte, aunque el art. 42 ET es el precepto central en la regulación de la materia, la regulación laboral del fenómeno descentralizador se extiende por otras normas de la disciplina, sin que el precepto de referencia se detenga a realizar las conexiones pertinentes, lo que ha dado lugar a dudas interpretativas. Es el caso de los arts. 168.1 Real Decreto Legislativo 8/2015, de 30 de octubre, por el que se aprueba el texto refundido de la Ley General de la Seguridad Social, BOE de 31 de octubre (en adelante, LGSS) y 24 de la Ley 31/1995, de 8 de noviembre, de prevención de riesgos laborales, BOE de 10 de noviembre (en adelante, LPRL) y, en particular, de la Ley 32/2006 de 18 de octubre, reguladora de la subcontratación en el Sector de la Construcción, BOE de 19 de octubre (en adelante, Ley subcontratación de la construcción). En la misma lógica, la letra del art. 42 ET genera dudas sobre el ámbito de aplicación de sus múltiples apartados. Existe cierto consenso en torno a la tesis que defiende que los dos primeros únicamente resultan aplicables a las contratas de la propia actividad, mientras que el resto serían aplicables a todas las contratas, pero la letra del precepto abona interpretaciones contradictorias. Tampoco ayuda la redacción del artículo a resolver los problemas interpretativos en torno a la distribución de responsabilidades en las cadenas de subcontratación de las que, en ocasiones, forman parte un número notable de empresas (Cruz Villalón, J., 1992). 


\subsection{La desprotección de las personas que prestan servicio en actividades complementarias}

La regulación en la materia ofrece dos niveles de protección para las personas empleadas en la realización de las actividades subcontratadas, que limitan de manera injustificada la eficacia del mecanismo legal de garantías. La determinación de qué tipo de actividades deben ser incluidas en el bloque de protección reforzada y cuáles en el bloque de protección básica es objeto de debate doctrinal y jurisprudencial. La tesis mayoritaria interpreta que los apartados primero y segundo del art. $42 \mathrm{ET}$ configuran el sistema de garantías reforzado, reservado a los supuestos en que la empresa principal contrate obras o servicios que puedan ser incluidas en su propia actividad. En tales casos, el empresario principal responde solidariamente por las deudas contraídas durante el periodo de ejecución de la contrata por el empresario contratista o subcontratista con los trabajadores empleados en la ejecución de la obra o el servicio contratado. De las deudas salariales responderá durante un año, a contar desde la finalización del encargo, pero si se trata de deudas de seguridad social, el plazo se amplía hasta tres años, a contar desde la misma fecha. Adicionalmente, cuando la contrata de propia actividad se desarrolle en el centro de trabajo de la principal, el art. 24.3 LPRL considera responsable al empresario del cumplimiento de las normas de prevención de riesgos laborales. Por el contrario, las personas empleadas en actividades que no formen parte de la propia actividad de la empresa principal no gozan de estas mismas garantías al quedar al margen del ámbito de aplicación de los apartados primero y segundo del art. $42 \mathrm{ET}$ y del art. $24.3 \mathrm{LPRL}$. El bloque de protección básica resulta por tanto bastante débil, la responsabilidad se transforma en subsidiaria y solo alcanza a las deudas por prestaciones de seguridad social, ahora por aplicación de lo dispuesto en el art. 168.1 LGSS. En otras palabras, en contratas de actividades complementarias no existen garantías legales sobre las deudas salariales que puedan alcanzar al empresario principal, salvo las que puedan derivarse de la aplicación de lo dispuesto en el art. 1.597 Código Civil.

A partir de este dato, la referencia normativa al concepto propia actividad se convierte en clave de arco del sistema laboral de garantías (Gómez Gordillo, R., 2017b). Los arts. 4 Decreto 3677/1970, de 17 de diciembre (BOE 4 de enero de 1971) y 19.2 Ley 16/1976, de 8 de abril, de Relaciones Laborales (BOE de 21 de abril) alumbraron y dieron continuidad a un concepto hoy vetusto que, sin embargo, ha ido superando las sucesivas reformas normativas operadas antes y después del periodo que preside la vigente norma constitucional. Curiosamente, la exposición de motivos de la primera justificaba la oportunidad de regular la materia por «las profundas transformaciones experimentadas por la estructura de las relaciones laborales», motivación que también debiera impulsar ahora una reforma integral del precepto. El legislador consideraba preciso salvaguardar los derechos de los trabajadores frente a actuaciones fraudulentas en la contratación y en el empleo; para ello la norma prohibía y sancionaba la cesión 
de trabajadores (arts. 1 a 3) y establecía la responsabilidad solidaria del empresario principal respecto de las deudas contraídas por el empresario auxiliar con sus trabajadores y con la seguridad social durante el periodo de vigencia de la contrata de obras o trabajos correspondientes a su propia actividad (art. 4). El sistema de comunicación de responsabilidades pretendía desplegar una triple funcionalidad: prevención del fraude, aseguramiento de pagos, y saneamiento del mercado de contratas.

La responsabilidad del empresario principal no se justificaba en la comisión de fraude alguno, ni era preciso acreditar relación laboral entre éste y las personas que prestan servicio en la contrata. Por el contrario, se considera responsable solidario del pago a quien toma la decisión de externalizar parte de su actividad, a quien escoge qué contratista asume dichas tareas y, sobre todo, a quien es el beneficiario último de la utilidad patrimonial que genera la prestación que realizan las personas que trabajan por cuenta de la empresa contratista (STS de 17 de mayo de 1996, rcud. n. ${ }^{\circ}$ 1902/1995). La empresa acuerda la externalización de parte de su actividad con la intención de mejorar su margen de beneficio o, simplemente, porque no posee las capacidades necesarias para realizar directamente ciertas actividades. En ambos casos debe poner en práctica un juicio de ponderación a partir de la activación de una pluralidad de criterios. La norma le obliga a que incluya en su análisis un dato adicional, la empresa seleccionada debe estar en condiciones de hacerse cargo de sus gastos laborales y de seguridad social. En términos más simplificados: "quien está en condiciones de obtener un beneficio debe de estar también dispuesto a responder de los perjuicios que se puedan derivar del mismo" (Soriano Cortés, D., 2007). El argumento precedente no permite vislumbrar qué motivos justifican la existencia de un doble nivel de protección, pues las razones que aconsejan su introducción en supuestos de propia actividad debieran recomendar también su extensión al resto de contratas (Gómez Gordillo, R., 2018).

\subsection{La discutible interpretación restrictiva del concepto propia actividad}

El concepto propia actividad permite situar al margen de la protección del mecanismo de garantía de pagos a las contrataciones realizadas por la empleadora por razones ajenas a su actividad empresarial. A pesar de ello, el art. 42.2 ET in fine, reitera esta exclusión de forma expresa y, a modo de ejemplo, cita las obras de construcción o reparación de la vivienda del empleador. La mención legal en estos términos puede considerarse innecesaria o redundante, aunque ha servido para defender que la voluntad del legislador laboral es establecer un doble régimen jurídico para las contrataciones realizadas por razón de la actividad empresarial. La necesidad o adecuación de establecer reglas diferenciadas en atención al tipo de actividad empresarial externalizada se justificó inicialmente en los distintos efectos de la decisión empresarial sobre la plantilla de la empresa comitente (Rodríguez Piñero, M., 1972). En el caso de la contratación 
de actividades propias se produciría un efecto sustitutivo sobre la prestación directa de la mano de obra, mientras que en el supuesto de contrataciones de actividades complementarias dicho efecto no se produciría. En esta lógica, la regla ejercería un protagonismo preventivo respecto de la articulación de sistemas de producción diseñados con el objetivo de desplazar el riesgo de la comitente en perjuicio de los intereses de las personas empleadas en la contrata que, por otra parte, permanecen ajenos a la adopción de estas decisiones. La comunicación de las responsabilidades por las deudas laborales entre contratista y comitente debe entonces limitarse a las actividades que constituyen el objeto social de la empresa, pues únicamente respecto de éstas se concreta el citado efecto sustitución. Visto desde el momento presente, el criterio resulta de difícil traslación pues, en línea de principio, todas las actividades empresariales, nucleares o complementarias, podrían realizarse con personas contratadas directamente por la empresa principal o mediante el recurso a la contratación de otras empresas. Permanecerían al margen de la anterior afirmación aquellas actividades que, por razones de especialización productiva, la empresa comitente no pudiera, en términos materiales, realizar. Pero también en este caso la diferenciación resulta de gran dificultad, pues los elementos tecnológicos y el how know necesarios, al menos en hipótesis, pueden ser objeto de adquisición.

En todo caso, la doctrina pronto advirtió de la complejidad aplicativa de un criterio que obligaba a estudiar, caso por caso, las actividades de ambas empresas para definir el régimen normativo aplicable, sobre la base de un criterio dotado de perfiles difusos, sometido a los efectos de la evolución de las prácticas organizacionales (SORIANO Cortés, D., 2007: p. 104) (Nores Torres, L.E., 2004: p. 87). Como era de esperar, la polémica se trasladó al ámbito judicial en el que distintas tesis hicieron fortuna, siguiendo una tendencia evolutiva claramente restrictiva. En un principio, se invocó la tesis de la «indispensabilidad" para considerar que formaban parte de la propia actividad de la empresa las actividades necesarias o imprescindibles para la concreción del objeto empresarial. En aplicación de esta teoría, en el ámbito de aplicación del bloque de protección reforzada quedaban incluidas dos tipos de contrataciones: las referidas a actividades que componen el ciclo de producción de la empresa y las referidas a tareas de carácter complementario. Con posterioridad, se fue consolidando la tesis de la «inherencia», según la cual solo formarían parte de la propia actividad de la comitente aquellas tareas inherentes al ciclo productivo de ésta, con exclusión de aquellas otras que no forman parte del núcleo de producción o de prestación de servicios (STS de 18 de enero de 1995, rcud. n.o 150/1994).

Como se ha dicho más arriba, esta segunda tesis se justifica mediante un criterio teleológico cargado de razón. El legislador laboral habría introducido el concepto de propia actividad con el objetivo de evitar que la responsabilidad por deudas laborales se extendiese al conjunto de la actividad empresarial, reservando esta fórmula de aseguramiento para aquellas tareas que le son más afi- 
nes. No comparto, sin embargo, la conclusión comúnmente enunciada sobre la base de este argumento, pues en mi opinión no resulta obvio que la tesis de la indispensabilidad no permita satisfacer el criterio del doble grado de protección. En este sentido, convendría señalar que el género actividades empresariales no se circunscribe a las especies actividades nucleares y actividades complementarias. La empresa realiza también contrataciones ajenas al proceso de elaboración de bienes o prestación de servicios. Entre otras, los contratos realizados para la puesta en marcha de la empresa, para la renovación o para la transformación de la organización empresarial, los relativos a la publicidad o al lanzamiento de nuevos productos, los estudios de mercado y otras muchas actividades que no pueden considerarse actividades de producción o de prestación de servicios.

Por otra parte, la tesis jurisprudencial del ciclo productivo ha limitado paulatinamente su inicial carácter restrictivo, para confundirse en algunos pronunciamientos con la tesis de la indispensabilidad, aunque en este caso no ha habido expresa manifestación de cambio de doctrina. No obstante, los pronunciamientos judiciales que se muestran favorables a mantener y aplicar la tesis de la inherencia realizan afirmaciones que bien pueden defenderse desde posiciones más cercanas a la tesis de la indispensabilidad, como cuando para determinar si una contrata forma parte de la propia actividad de la empresa comitente el tribunal se cuestiona si «de no haberse concertado ésta, las obras y servicios debieran realizarse por el propio empresario comitente so pena de perjudicar sensiblemente su actividad empresarial» (STS n. ${ }^{\circ}$ 56/2020, de 23 de enero, rec. 396/2017).

\subsection{La existencia de otros mecanismos de aseguramiento de las deudas salariales y de seguridad social}

Como es sobradamente conocido, el art. 42 ET no es el único precepto que asegura el pago en supuestos de contratas y subcontratas en el ordenamiento jurídico laboral español. La pluralidad de instrumentos de garantía salarial o prestacional que en la actualidad posee el ordenamiento laboral permite afirmar que, en última instancia, las garantías de pago de las deudas salariales y de seguridad social que ofrece el art. 42 ET tienen hoy como destinatario principal al Estado. La eventual insolvencia del empresario contratista puede ser en parte cubierta por el Fondo de Garantía Salarial (art. 33 ET), o vía acción directa por el art. 1.597 C. Civil, mientras que el principio de automaticidad, que opera sobre las prestaciones de seguridad social ex art. 167 LGSS, impide que los impagos del empleador afecten o menoscaben los derechos en materia de prestaciones de las personas que prestan servicio en contratas o subcontratas. Sin perjuicio de lo anterior, no puede negarse que la pluralidad de garantías de cobro obra también en favor de los intereses de las personas trabajadoras, y que la fórmula que obliga a la empresa principal a hacerse cargo de estas deudas a petición de la acreedora resulta un instrumento de gran eficacia a estos efectos. Por consiguiente, aunque la relevancia de la previsión estatutaria ha ido disminuyendo desde su aparición, 
tanto por la interpretación restrictiva del concepto propia actividad, como por la aparición de otras fórmulas de salvaguarda de los intereses de las personas trabajadoras, continúa siendo el mecanismo más eficaz para garantizar las deudas salariales y de seguridad social. La nueva regulación podría mejorar la protección, extendiendo el alcance de la garantía al conjunto de las deudas retributivas y, sobre todo, reformulando o eliminando el requisito de la propia actividad, para tutelar los derechos de las personas que prestan servicio en contratas de actividades complementarias.

\subsection{La débil protección ofrecida por los mecanismos de información y representación}

Menores discrepancias existen en torno alcance general, para todo tipo de contratas, de los derechos de información y representación previstos en los apartados 3 a 7 del art. $41 \mathrm{ET}$, seguramente porque no llevan aparejados eventuales costes para la empresa principal. Los apartados 3, 4 y 5 fueron introducidos en 2001, mientras que la aparición de los apartados 6 y 7 se demoró hasta el año 2006. Obviamente, los derechos de información, tanto individuales como colectivos, ofrecen un mayor grado de transparencia y pueden ser un presupuesto necesario para el ejercicio de otros derechos, pero, aisladamente considerados, su eficacia para garantizar los derechos laborales resulta muy limitada. Por su parte, la dificultad formal y material de acceso a la representación de los trabajadores no parece que haya disminuido de manera apreciable. A mayor abundamiento, la referencia legal al derecho de reunión de las distintas representaciones de los trabajadores de las empresas que comparten de forma continuada un mismo lugar de trabajo, ni genera nuevas garantías, ni legaliza posibilidades de relación entre representantes suficientemente amparadas por la libertad sindical. La referencia a la posibilidad de que los representantes trabajadores de las contratas hagan uso de los locales de la empresa cedidos a la representación de los trabajadores de la principal, contenida en el art. $81 \mathrm{ET}$, resulta insuficiente y problemática, al quedar condicionada a la existencia de un acuerdo con la empresa sobre el particular y, en ocasiones, a la posibilidad de que una interpretación literal del precepto obligue a la representación de sus trabajadores a compartir espacios habitualmente escasos. Por otra parte, el estrecho canal de representación que se ofrece a los trabajadores de la contrata que carecen de ella tampoco ha satisfecho las necesidades de este colectivo.

\subsection{La inadecuación del contrato de obra o servicio para la cobertura de las necesidades de la empresa contratista}

Sin perjuicio de la insuficiencia de los mecanismos específicos de garantía, a los que se ha hecho referencia más arriba, la duración determinada de los contratos de las personas que prestan servicio por cuenta de la contrata ha sido una de las causas que ha alimentado de manera más notable el proceso de desarticu- 
lación de la tutela jurídico laboral y la generalización de situaciones de precariedad en el ámbito objeto de estudio. Durante un periodo que se ha extendido más de dos décadas, las empresas contratistas han hecho uso de la modalidad de contrato temporal prevista por el art. 15.1.a ET, para cubrir las necesidades de mano de obra derivadas de la celebración de una contrata, posibilidad legitimada, entre otras muchas, por la STS de 15 de enero de 1997, rcud. 3827/1995 (Saguineti Raymond, W., 2021). Hasta dicho pronunciamiento, nuestros tribunales habían mantenido un criterio más restrictivo, que impedía el uso de esta modalidad contractual en tales supuestos (STS de 26 septiembre 1992, rcud. 2376/1991). El cambio de doctrina se justificó, en su momento, con el argumento de que la celebración del contrato entre empresas generaba una necesidad de trabajo temporalmente limitada, objetivamente definida y conocida por ambas partes en el momento de la firma del contrato de trabajo. En aplicación de esta doctrina, durante estos años se ha admitido la vinculación de la duración del contrato de trabajo a la vigencia de la contrata, con inclusión de las eventuales y sucesivas prórrogas.

La flexibilización del criterio jurisprudencial facilitó el desarrollo de los procesos de descentralización productiva y el abuso del recurso a la contratación temporal. La comprobación de los efectos negativos que la tesis jurisprudencial generaba determinó una rectificación parcial de la doctrina jurisprudencial, mediante la imposición de determinados límites. En concreto, la STS n. 4975/2007, de 14 de junio de 2007, rec. 2301/2006, consideraba que el cese anticipado de la contrata por acuerdo entre las empresas no justificaba la automática extinción de los contratos de trabajo de las personas contratadas a tal fin. Con posterioridad, la STS n. ${ }^{\circ} 3491 / 2008$, de 10 de junio de 2008, rcud. $1204 / 2007$, niega también la posibilidad de dar por finalizados algunos de los contratos de duración determinada celebrados para la atención de la contrata cuando el comitente reduce sus necesidades de mano de obra ajena.

La preocupación por la evolución del sector indujo también la actuación del legislador, que procedió a limitar la extensión temporal de estos contratos (art. 1 $\mathrm{RDL}$ 10/2010, de 16 de junio, de medidas urgentes para la reforma del mercado de trabajo, BOE de 17 de junio). La reforma no pretendía reconducir el criterio jurisprudencial, pero limitaba la duración de estas contrataciones, entendiendo que superado el límite legal ( 3 años) o convencional ( 4 años) las tareas contratadas gozan de naturaleza permanente y, por consiguiente, deben ser cubiertas mediante contratos de duración indefinida. La eficacia de la reforma quedó en parte mermada por lo dispuesto en la Disp. Trans. 1. a del mismo texto normativo, que situó fuera del ámbito de aplicación del precepto a los contratos concertados con anterioridad a su entrada en vigor. La exclusión legal ha permitido que algunos contratos de duración determinada hayan permanecido vigentes hasta la fecha presente, mientras que el generalizado fraude en materia de contratación temporal que padece nuestro sistema de relaciones laborales ha favore- 
cido un alto grado de rotación de personas, en aquellos contratos celebrados con posterioridad a la entrada en vigor de la norma limitativa.

Conocedor de esta realidad, el TS se reafirma en su tendencia restrictiva en varios pronunciamientos relativamente recientes. Las SSTS n. ${ }^{\circ}$ 3243/2008 y n. ${ }^{\circ} 3308 / 2008$, de 19 de julio de 2018, declaran que las sucesivas modificaciones de la contrata original desdibujan la previsibilidad del límite temporal que caracteriza a los contratos de obra o servicio determinado transformándolos en indefinidos. Con posterioridad, la STS n. ${ }^{\circ}$ 4248/2020, de 10 de diciembre, rcud. 1858/2018, declara aplicable la regla sobre la concatenación de contratos, establecida en el art. 15.5 ET, en un supuesto de subrogación del contratista entrante en los contratos de trabajo de la saliente. Semanas más tarde, la STS n. ${ }^{\circ} 4383 / 2020$, de 29 de diciembre de 2020, rcud. 240/2018, confirma el cambio de rumbo, y realiza una rectificación integral de la doctrina en la materia, negando la idoneidad de la modalidad contractual prevista en el art. 15.1.a ET en supuestos de contrata "cuando la actividad de la empresa no es otra que la de prestar servicios para terceros». La sentencia permite revalorizar los criterios de autonomía y sustantividad poniéndolos en contacto con el proceso productivo de la empresa contratista.

La renovada jurisprudencia en la materia podría solucionar los problemas de abuso de la contratación temporal en el sector de las contratas de obras y servicios, aunque el legislador no debiera dejar en manos de los jueces toda la responsabilidad en este apartado. Algunos pronunciamientos judiciales previos (STS n. ${ }^{\circ}$ 3243/2008, de 19 de julio, rcud. 823/2017) señalaban en dicha dirección, el legislador haría bien en atender estos llamamientos para reforzar la prohibición de recurrir a este tipo de contratos en supuestos de contratas, mediante una exclusión general, a efectos declarativos, incluida en el art. 15.1.a ET.

\subsection{La cuestionada aplicabilidad del art. 44 ET en supuestos de sucesión de contratas}

Los cambios en la titularidad de la contrata, y sus efectos sobre la estabilidad en el empleo y sobre las condiciones de trabajo de las personas afectadas, constituyen una fuente de problemas en nuestro sistema, que no han sido adecuadamente solucionados ni por los cambios normativos, en esta materia claramente influenciados por las normas de la UE, ni por la recurrente intervención de la jurisprudencia estatal y de la UE, ni por la actuación de la negociación colectiva (Gómez Gordillo, R., 2019). La situación de inseguridad jurídica se ha visto incrementada tras el sentido del fallo de la sentencia Somoza Hermo (STJUE de 11 de julio de 2018, asunto C- 60/2017), pronunciamiento que ańade tensiones en el proceso de renovación de los convenios colectivos de determinados sectores, que han venido generando un imperfecto y complejo sistema de garantía de continuidad y mantenimiento de las condiciones de trabajo de los contra- 
tos vinculados a la realización de la contrata que cambia de titular, aplicable en sectores de la actividad masivamente externalizados. Conforme a esta reciente doctrina, enésimo pronunciamiento que ha coronado el diálogo sobre el particular que el Tribunal Europeo mantiene con el Tribunal Supremo desde hace décadas, si la empresa entrante asume, en cumplimiento de lo establecido en el convenio colectivo aplicable, los contratos de trabajo vigentes de la contrata saliente, la subrogación operada debe realizarse en los términos y condiciones establecidos por el art. 44 ET. Por esta vía, la subrogación de contratas prevista en convenio colectivo, que en principio operaría al margen de la regulación legal, pasa a integrar el ámbito de aplicación del mencionado precepto legal. En otras palabras, la novación subjetiva del empresario en los contratos de trabajo de la saliente se alza como causa y efecto del supuesto legal. En la práctica, cuando los negociadores de un convenio colectivo sectorial acuerdan una cláusula de este tipo, atraen la aplicación del conjunto de reglas contenidas en el art. 44 ET y, por consiguiente, la nulidad de cualquier cláusula convencional que tenga por objeto modificar los efectos legales de la subrogación, cuando es acordada en detrimento de los intereses de las personas trabajadoras. El análisis de una cuestión tan espinosa aconseja incluir los cambios en la titularidad de las contratas en el ámbito de aplicación del art. 44 ET, para dotar de seguridad jurídica a una regulación ya sometida a profundos cambios.

\subsection{La permeable frontera entre cesión ilegal y lícita contrata}

Ya se ha dicho que la originaria regulación de la actividad en contratas y subcontratas surgía en paralelo a la ordenación de la cesión ilegal, como fórmula de materializar el principio que niega la condición de mercancía al trabajo humano. La reforma más relevante en la materia, más allá de la legalización de la actividad de suministro de mano de obra para las empresas de trabajo temporal, fue operada en 2006, y procedió a reconocer la insuficiencia de la regulación entonces vigente para deslindar de manera clara ambos fenómenos. La operación de reforma resolvió, con la adición de un nuevo apartado segundo al art. 43 ET, complementar el precepto con la introducción de una serie de presunciones elaboradas a partir de los indicios que la doctrina judicial venía manejando.

El trascurso del tiempo ha venido a demostrar que la positivación de indicios de origen jurisprudencial mejora, pero no resuelve, los problemas de delimitación conceptual. A fecha de hoy, la frontera entre la cesión ilegal y la subcontratación lícita continúa siendo excesivamente difusa en la práctica de las relaciones laborales, especialmente en los supuestos en que las empresas contratistas realizan su tarea en el centro de trabajo de la comitente. En estos casos, las empresas contratistas no suelen hacer uso de una significativa infraestructura material, por lo que el sistema de presunciones establecidos en el art. 43.2 ET, en muchos casos, se concreta en la exigencia de que el empresario contratista «ejerza las funciones inherentes a su condición de empresario». En la práctica, 
la doctrina judicial en la materia permite simular el ejercicio de estas facultades a partir del cumplimiento formal de todos o de alguno de los indicios señalados en los numerosos pronunciamientos judiciales. Es cierto que la reforma de 2006 no incorporó todos los criterios manejados por la doctrina judicial y, en particular, olvidó incluir el elemento de la autonomía técnica de la contrata. La inclusión de este criterio puede coadyuvar a mejorar la situación, pero incidir en una estrategia legal ya probada quizás no sea la mejor alternativa. Ante estas dificultades, quizás la estrategia más eficaz pase por desincentivar el recurso a estas fórmulas de organización empresarial.

\section{Alcance y orientación de las propuestas de reforma conocidas hasta la fecha}

El acuerdo de gobierno entre el Partido Socialista Obrero Español y Unidas Podemos, celebrado el pasado día 30 de diciembre de 2019, compromete a sendos partidos a reformar la regulación contenida en el art. 42.1 ET «a efectos de limitar la subcontratación laboral a servicios especializados ajenos a la actividad principal de la empresa». La parca mención sobre la materia señala un objetivo de difícil concreción que, desde el punto de vista teórico, podría ser alcanzado por distintas vías. Asegurar que las empresas limiten el recurso al auxilio de otras empresas a motivaciones de carácter técnico constituye un objetivo que puede abordarse desde la prohibición, opción que, prima facie, podría vulnerar otros derechos y libertades, o mediante incentivos negativos que pudieran tener mejor encaje legal. En todo caso, en ausencia de borradores que pudieran haber sido puestos sobre la mesa del diálogo social, no cabe más que analizar el texto de la Proposición de Ley de modificación del artículo 42.1 del ET para garantizar la igualdad en las condiciones laborales de los trabajadores subcontratados, presentada por el PSOE el 8 de agosto de 2016 (BOCG de 9 de septiembre de 2016), y de las enmiendas presentadas por los partidos representados en el Congreso de los Diputados en la legislatura precedente (BOCG de 3 de mayo de 2017), por más que no se ignore que dicho procedimiento, en su momento, caducó sin que las distintas propuestas llegasen a ser discutidas en el Pleno.

La iniciativa parlamentaria plantea la necesidad de reformar el art. 42 ET para la consecución de tres objetivos fundamentales. En primer lugar, se propone mejorar el grado de seguridad jurídica mediante la introducción de una serie de parámetros que faciliten la identificación del concepto propia actividad. En segundo lugar, la propuesta señala prácticas de competencia desleal entre empresas que forman parte de un mismo sector de la actividad económica, mediante la puesta en marcha de procesos de degradación de las condiciones de trabajo; dicho, en otros términos, la propuesta describe cómo la externalización de actividades provoca situaciones de dumping social, fundamentalmente mediante 
la reducción de la cuantía de las retribuciones y el incremento de los tiempos de trabajo, y genera competencia desleal entre empresas centralizadas y empresas con procesos productivos descentralizados. Como colofón de todo lo anterior, la propuesta pretende poner en marcha un mecanismo de igualación de condiciones de trabajo entre los trabajadores de la empresa principal y contratista, similar al establecido para las Empresas de Trabajo Temporal. De alguna manera, la propuesta de reforma retoma los tres objetivos de la regulación originaria (prevención del fraude, aseguramiento de pagos y saneamiento del mercado de contratas) e incorpora un objetivo adicional, la mejora de las condiciones de trabajo de las personas empleadas por contratas y subcontratas.

Por su parte, las enmiendas presentadas por los distintos grupos parlamentarios, incluido el Grupo Socialista, proponen profundizar en la reforma de otros aspectos. En concreto, aunque se mantiene la estructura de los mecanismos de protección vigentes, edificada sobre un bloque de protección reforzada, para contratas de la propia actividad, un bloque de protección básica, para el resto de contratas, y facultades de información y representación especialmente intensas en los supuestos de contratas que prestan servicio en el centro de trabajo de la empresa principal, el alcance y la intensidad de los mecanismos de protección propuestos resulta más completa y eficaz. Adicionalmente, se propone la mejora de la definición de algunos conceptos legales, en particular, el concepto de cesión ilegal.

\subsection{Norma laboral, libertad de establecimiento y libertad de empresa}

La jurisprudencia española incardina las decisiones sobre externalización productiva, como el resto de las relativas a la ordenación del proceso de producción de bienes o servicios, en el ejercicio de las facultades empresariales protegidas por el art. 38 CE (STS n. ${ }^{\circ}$ 5791/2015, de 20 de noviembre). Sin perjuicio de lo anterior, esta libertad puede ser limitada por el legislador ordinario, como implícitamente reconoce también la jurisprudencia cuando afirma que «el ordenamiento jurídico no contiene ninguna prohibición general que impida al empresario recurrir a la contratación externa para integrar su actividad productiva» (STS n. ${ }^{\circ}$ 9880/2001, de 17 de diciembre, rcud. 104/2015). Es obvio que las eventuales limitaciones que sobre el ejercicio de esta libertad puede imponer el legislador en el ámbito laboral deben justificarse, como dice la sentencia citada, en la finalidad de «evitar que por esta vía puedan vulnerarse derechos de los trabajadores». Por tanto, podría concluirse que una regulación limitadora de las facultades empresariales de externalización de la actividad por motivaciones ajenas a la especialización productiva, en la medida en que estas decisiones pudieran vulnerar los derechos de los trabajadores, no es radicalmente contraria al marco normativo constitucional español.

En la misma lógica, una regulación restrictiva de las facultades de organización empresarial podría afectar las libertades de establecimiento y libre pres- 
tación de servicios (Pérez de los Cobos Orihuel, F., 2020) y, por este motivo, verse sometida al control del TJUE. En tal caso, las autoridades españolas se verían obligadas a demostrar que la reforma resulta necesaria para garantizar los derechos de los trabajadores subcontratados a disfrutar de unas condiciones de trabajo dignas (art. 31 Carta de los Derechos Fundamentales de la Unión Europea) y, conforme al principio de proporcionalidad, que no resulta posible alcanzar dicho fin con la aplicación de normas menos rigurosas. Es evidente que sobre la posibilidad de explorar vías menos invasivas para garantizar la consecución del objetivo propuesto resulta de mayor dificultad alcanzar un acuerdo, pues las medidas posibles son numerosas, casi infinitas, y la certeza sobre el éxito de la acción normativa requiere un ejercicio de predicción muy condicionado por elementos de carácter subjetivo.

Por todo ello, y en atención a los argumentos precedentes, pudiera entenderse que la metodología jurídicamente más segura de intervención normativa en la materia vendría de la mano de la introducción de incentivos negativos que desanimen a las empresas a subcontratar actividades con el objetivo de reducir los costes de personal. Esta opción cuenta ya con algunas experiencias que no han recibido reproche por parte de los tribunales estatales y ni de la UE. Es el caso, entre otros, del art. 5 de la Directiva 2008/104/CE del Parlamento Europeo y del Consejo, de 19 de noviembre de 2008, relativa al trabajo a través de empresas de trabajo temporal (DOUE de 5 de diciembre), que establece un principio de igualdad de trato entre los trabajadores de la empresa usuaria y los trabajadores de la ETT, que afecta a las condiciones esenciales de trabajo. En todo caso, conviene tener presente que el art. 4 de la misma norma hace referencia expresa a la posibilidad de restringir la actividad de este tipo de empresas, "por razones de interés general relativas, sobre todo, a la protección de los trabajadores cedidos por empresas de trabajo temporal, a las exigencias en materia de salud y seguridad en el trabajo o a la necesidad de garantizar el buen funcionamiento del mercado de trabajo y de evitar posibles abusos».

\subsection{Igualación de condiciones laborales y de empleo y propia actividad}

El establecimiento de un principio de igualación de condiciones de trabajo, aplicable a las personas que prestan servicio por cuenta de una empresa contratista, garantizaría que, durante el tiempo de ejecución de la contrata, quienes participan del proceso de elaboración de un bien o de la prestación de un servicio mantengan similares "condiciones laborales y de empleo", con independencia de su adscripción formal a la empresa principal o contratista. Con bastante probabilidad, la adopción de este mecanismo de equidad mejoraría las condiciones de trabajo en muchas empresas, e incrementaría los costes de las operaciones de externalización no justificadas por razones de especialización productiva, desincentivando el recurso a esta nociva práctica. 
El término de referencia para la operación de igualación de condiciones de trabajo propuesto es «el convenio colectivo que fuese de aplicación en la empresa principal o, en su caso, las que tendrían si fueran trabajadores contratados directamente por dicho empresario principal», expresión que debe entenderse referida tanto a los convenios colectivos sectoriales como a los convenios colectivos de empresa, a los acuerdos de empresa, a los convenios extraestatutarios e, incluso, a las condiciones fijadas por voluntad unilateral del empleador.

Por otra parte, la propuesta original se detiene a especificar el alcance material de la previsión y enumera, como parte de las condiciones esenciales de trabajo y empleo, las referidas «a remuneración y cuantía salarial, condiciones de contratación, tiempo de trabajo y descanso, igualdad, protección de la maternidad, lactancia y paternidad y frente a riesgos laborales». En este apartado la propuesta no resulta particularmente afortunada desde el punto de vista técnico, si bien podría entenderse que la referencia a la remuneración está relacionada con la estructura retributiva, mientras que la idea de cuantía salarial tendría por objeto excluir los conceptos extrasalariales. Más extensa y comprensiva del conjunto de materias relacionadas con el concepto de jornada de trabajo puede considerarse la referencia al tiempo de trabajo y descanso que, en mi opinión, se extendería a la regulación de la materia in toto, incluyendo las reglas sobre permisos y vacaciones.

El debate sobre la delimitación del concepto condiciones esenciales parece cerrarse con la enmienda n. ${ }^{\circ}$ 27, presentada por el Grupo Socialista, que en supuestos de propia actividad impone la aplicación del convenio colectivo aplicable a la empresa principal, «salvo que las condiciones del propio convenio fueran equivalentes», aunque puede generar alguna otra dificultad interpretativa. La enmienda resuelve de un plumazo la discusión en torno al alcance material del mecanismo igualador, pero no tiene en cuenta la dificultad de igualar determinadas condiciones, en particular alguna de las relacionadas con cuestiones de acción social o materias sindicales. Por otra parte, la referencia al convenio excluiría condiciones de trabajo fijadas por otras vías. Y, por último, la comparación entre convenios resulta compleja incluso cuando se utiliza la regla tradicional de aplicación del convenio colectivo más favorable. En esta ocasión se introduce una novedad, la enmienda hace referencia al convenio colectivo con condiciones equivalentes, circunstancia que eleva la complejidad de la operación de comparación. En mi opinión, la igualación de condiciones de trabajo debe regularse a partir de institutos jurídicos ya conocidos, estrategia que genera mayor seguridad jurídica sobre el alcance de la reforma.

La enmienda n.o 2, presentada por el Grupo Unidos Podemos-En Comú Podem-En Marea (en adelante, Unidos Podemos), más allá de proponer la especificación de la materia relativa a la distribución de la jornada, aporta una relevante novedad relativa a las condiciones aplicables a las contratas que no corresponden a la propia actividad de la comitente, que transforma en norma jurídica 
el criterio jurisprudencial para considerar aplicable el convenio colectivo del sector de la actividad que desarrolla la contrata, sin perjuicio de la posibilidad de aplicar el convenio colectivo de empresa en caso de que este último fijase condiciones más favorables. La enmienda n. ${ }^{\circ} 27$, presentada por el Grupo Socialista, comparte literalmente el mismo criterio.

Como se ha visto, estas propuestas mantienen el protagonismo de la naturaleza de la actividad en la determinación del régimen jurídico aplicable. Los criterios interpretativos que durante estos años han acompañado al mecanismo han provocado el amparo de los grupos que precisan una menor protección, al tiempo que se desatiende a los colectivos que gozan de menos instrumentos de protección, cuyo número crece en paralelo a la evolución de la organización empresarial. Quizás por ello las propuestas de reforma inciden también sobre la definición de este polémico concepto. La propuesta original mantenía en lo sustancial la tesis de la inherencia, señalando como objeto de protección la realización de "todas o alguna de las actividades principales o nucleares» de la empresa comitente. En mi opinión, la propuesta original podría materializar un cierto paso atrás en la evolución de nuestra jurisprudencia, restringiendo de manera notable la eficacia de la reforma. En la misma línea, la enmienda n. ${ }^{\circ} 21$, presentada por Ciudadanos incidía en la tesis de la inherencia, circunscribiendo el ámbito de aplicación del art. 42.2 ET a las actividades «que se integren en el ciclo productivo de la empresa principal, de modo que formen parte inherente del producto o servicio que se elabora o se presta».

Por el contrario, aunque la enmienda n. ${ }^{\circ}$ 27, presentada por el Grupo Socialista, se aferra también a la tesis de la inherencia, en esta ocasión relacionada con el objeto social de la empresa, deja en manos de la autonomía colectiva la posibilidad de extender la aplicación del precepto a aquellas otras actividades «necesarias para la organización y realización del trabajo». La opción de encomendar a la negociación colectiva la disposición, en beneficio de las personas trabajadoras, del ámbito de aplicación de un sistema de garantías tan necesario y urgente no parece la mejor de las estrategias, en particular si se toma en consideración las dificultades que las organizaciones sindicales encuentran en el ámbito descrito para desarrollar las libertades reconocidas en la norma constitucional. A mayor abundamiento, la redacción de la cláusula genera dudas en torno a la selección de los negociadores habilitados a tal fin, y a la legitimación de los negociadores de un determinado sector para obligar a las empresas ubicadas en otro sector de la actividad. En todo caso, el éxito parcial de la actividad de los negociadores en este punto podría agravar la situación de desigualdad, ya existente, entre los distintos sectores de la actividad, derivada de la aplicación de convenios colectivos de diverso tenor y grado de garantismo.

Por último, la enmienda n. ${ }^{\circ}$ 2, presentada por Unidos Podemos, propone un concepto de propia actividad claramente más amplio, que considera parte 
de la propia actividad las labores necesarias para la organización y realización del trabajo, sin que en este caso se haga depender del convenio colectivo su inclusión. En la práctica, la propuesta retoma la tesis de la necesidad, defendida inicialmente por nuestros tribunales, como elemento básico para extender la protección del art. $42 \mathrm{ET}$ a los colectivos más afectados por los procesos de externalización, según se ha dicho más arriba. En todo caso, llama la atención la redacción, en dicha propuesta, de la cláusula que excluye del ámbito de aplicación del precepto la actividad de construcción o reparación de la vivienda, realizada por «el cabeza de familia». Más allá de la carga, desde la perspectiva de género, que sostiene la expresión, convendría extender la exclusión a las viviendas, en plural, propiedad de cualquier miembro de la familia, no sólo de aquellos empresarios o empresarias en quienes concurra la condición de padre o madre.

Particularmente novedosa es la regulación específica que la enmienda n. ${ }^{\circ} 2$ propone para las Administraciones Públicas, en cuyo caso se considera propia actividad «todas aquellas actividades inherentes a las competencias que ejerzan y servicios que deban prestar, así como aquellas actividades complementarias necesarias para su cumplimiento». Por su parte, también en este supuesto, la enmienda n. ${ }^{\circ} 27$ condiciona la inclusión de las actividades complementarias a su selección por la negociación colectiva.

\subsection{Subcontratación, información y representación de las personas trabajadoras en la empresa}

Más arriba se ha hecho referencia a las dificultades que las personas que prestan servicio por cuenta de una contrata o subcontrata encuentran a la hora de ejercer estos derechos, reconocidos con carácter general por los arts. 61 y ss. ET, y las limitaciones de la regulación específica sobre información y representación contenida en los apartados 3 a 7 del art. 42 ET, en particular cuando la tarea se realiza en el centro de trabajo de la empresa comitente. Pues bien, la propuesta original no planteaba mejora alguna en la materia, si bien las enmiendas presentadas por Unidos Podemos y el Grupo Socialista planean importantes novedades. En primer lugar, con relación a los derechos reconocidos en los apdos. 3, 4, 5 y 7 del art. $42 \mathrm{ET}$, se propone finiquitar las dudas en torno al alcance de tales previsiones, para expresamente señalar que tanto las contratas de la propia actividad como las de otras actividades se encuentran sujetas a lo previsto en tales apartados.

En segundo lugar, el derecho a ser informado de la identidad de la empresa principal se extiende también al conjunto de empresas que le preceden en la cadena de subcontratación, con el objetivo de que las personas trabajadoras tengan constancia de todas y cada una de las empresas contra las que puede eventualmente reclamar. La misma información debe ser puesta en conocimiento de la TGSS. 
En tercer lugar, la enmienda n. ${ }^{\circ}$ 5, presentada por Unidos Podemos, incorpora la obligación de que la representación de las personas trabajadoras de la contratista o subcontratista sea informada "documentalmente», sobre los extremos previstos en el art. 42.4 ET. En esta ocasión, la obligación no se extiende a la cadena de subcontratación y, en mi opinión, la referencia a la información documentada pudiera considerarse superflua, por redundante, si se atiende a la definición del derecho a la información prevista en el art. 64.1 ET.

En cuarto lugar, la enmienda n. ${ }^{\circ} 7$, presentada por Unidos Podemos, propone unificar, aunque introduciendo algo de confusión, los apartados 6 y 7 del art. 41 ET, aplicables como es conocido a las personas que prestan servicio en el centro de trabajo de la empresa comitente. En tales casos, la reuniones de coordinación de las representaciones de las personas trabajadoras, a las que se refiere el texto vigente, adquieren una perspectiva más proactiva y se transformarían en el ejercicio de una «labor coordinada en materia de organización del trabajo, condiciones de empleo, vigilancia y control en el cumplimiento de la normativa laboral, de Seguridad Social y en materia de prevención de riesgos laborales, a cuyos efectos recibirán información de todas las empresas sobre dichas materias y dispondrán de los locales y tablones de anuncios previstos en el art. 81». La previsión afecta a distintos derechos y facultades. Similar propuesta contiene la enmienda n. ${ }^{\circ} 27$. En todo caso, la relación de materias sobre las que la labor de las distintas representaciones podrá coordinarse no añade facultades que no pudieran desplegarse en el ejercicio de las libertades sindicales o de las atribuciones de la representación unitaria. Sin embargo, la obligación de informar al conjunto de las representaciones sobre dichas materias sí constituye un elemento novedoso que, sin duda, revaloriza y facilita el ejercicio de la actividad representativa. Por lo que hace referencia a la cuestión de los locales y tablones de anuncios, como se ha dicho más arriba, la posibilidad de compartir espacios escasos entre distintas representaciones puede provocar algunos conflictos, si bien, el reconocimiento del derecho al uso de locales y otros medios materiales por parte de la representación de las personas empleadas por las contratas y subcontratas debe valorarse positivamente.

Por último, las enmiendas n. 7 y 27 modifican de manera radical la regla vigente, y contenida en el art. 42.6 ET, relativa a posibilidad de que la representación de las personas trabajadoras de la comitente ejerza tareas de representación de las personas trabajadoras de contratas que carezcan de ella ante la empresa principal, y nunca con relación a reclamaciones respecto de la empresa contratista. La propuesta plantea básicamente que, en los mismos supuestos seńalados en la norma vigente, la representación unitaria de la empresa principal asuma la tarea de representar a quienes carecen de representación a todos los efectos e incrementando en su caso el crédito horario. En otras palabras, la representación unitaria de la empresa principal asume subsidiariamente las tareas de representación de las personas que prestan servicio para contratas y subcontratas en el centro de trabajo de la principal, aunque a los solos efectos de coor- 
dinación de las tareas más arriba mencionadas. Sin duda, la ambiciosa propuesta reduciría de manera eficaz las carencias advertidas. Más novedosa si cabe resulta la enmienda n. ${ }^{\circ} 8$, presentada por Unidos Podemos, que castiga con la presunción de que existe cesión ilegal los supuestos de incumplimiento de los deberes de información a los que hacen referencia los apartados 3 a 7 del art. 42 ET, cuando las empresas compartan centro de trabajo.

\subsection{La reordenación de la responsabilidad solidaria de la empresa comitente.}

La posibilidad de intensificar el mecanismo de responsabilidades como garantía del pago de las deudas que las empresas contratistas y subcontratistas pueden generar con las personas que prestan servicios en la ejecución de la contrata, se plantea en las enmiendas n. ${ }^{\circ} 3$ y 27 , que realizan similares propuestas de extensión de su alcance, en términos objetivos y subjetivos, si bien como se ha dicho más arriba, a partir de una definición distinta del concepto propia actividad, más extensa en las enmiendas presentadas por Unidos Podemos.

La primera novedad se refiere a la perfección del doble nivel de garantía, pues en ambos casos se propone establecer la responsabilidad subsidiaria de la empresa comitente respecto de las obligaciones laborales y de seguridad social cuando la contrata no sea de la propia actividad del comitente. En segundo lugar, se establece un sistema de responsabilidades múltiples, que recorre en sentido ascendente toda la cadena de subcontratación, de manera que las personas que prestan servicio en la última empresa subcontratista podrán reclamar a todas las empresas implicadas. En buena lógica, la imposición de responsabilidades va acompañada de una nueva obligación con la que cargarían todas las empresas contratistas y subcontratistas quienes, para subcontratar toda o parte de la actividad contratada, deberán solicitar el consentimiento previo de la empresa principal. Por su parte, la enmienda n. ${ }^{\circ} 21$ presentada por Ciudadanos, convierte aquel previo consentimiento en obligación de notificación. En ningún caso, se propone regulación relativa a las consecuencias jurídicas de la ausencia de consentimiento o comunicación que, en principio, no produciría efectos en el plano laboral, sin perjuicio de los que quepan imputar en el plano civil o mercantil.

Con relación a las modificaciones sobre el alcance objetivo de la garantía, las enmiendas 3 y 27 hacen referencia al conjunto de las obligaciones de naturaleza laboral, por lo que afectaría a todas las retribuciones e indemnizaciones, independientemente de su naturaleza salarial o extrasalarial, y de seguridad social, incluidos los compromisos de pensiones y demás obligaciones en materia de protección social complementaria.

\subsection{Hacia una mejora de la delimitación de los conceptos legales de aplicación}

Las enmiendas presentadas, en particular las n. 2 y n. ${ }^{\circ} 27$, realizan un importante esfuerzo de definición de los numerosos conceptos jurídicos que parti- 
cipan en la relación triangular y de diferenciación de los supuestos de contrata lícita y cesión ilegal de trabajadores. Aunque podría afirmarse que tales conceptos se encuentran bastante consolidados entre la doctrina y la jurisprudencia, la sistematización de los mismos en el texto legal merece positiva valoración. En concreto, en primer lugar, sendas enmiendas definen con similar amplitud conceptos como el de «empresario principal», «empresario contratista» y empresario subcontratista» y «encadenamiento de contratos». En este sentido, considero más correcto hablar de «empresa principal», "empresa contratista» y "empresa subcontratista», por más que la tradición de nuestro ET pudiera aconsejar mantener el término empresario, a pesar de que dicha posición comúnmente es ocupada por personas jurídicas. En segundo lugar, el contrato bilateral que vincula a ambas empresas debe tener forma escrita y podrá ser de naturaleza civil, mercantil o administrativa. En este apartado quizás la novedad más relevante es la exigencia de que el objeto del contrato debe poseer «autonomía y sustantividad propia», reiterándose la prohibición de que el objeto del contrato, en esencia, sea la aportación de mano de obra. Más allá de cuestiones técnicas que recomendarían eliminar reiteraciones en la redacción de los arts. 42 y 43 ET, la autonomía del objeto del contrato puede constituir una exigencia que obre en garantía de la competencia técnica de la contrata y, en ese sentido, estrechamente conectada con las exigencias que se enumeran en el párrafo posterior.

Son varias las enmiendas que tienen por objeto la delimitación del concepto de contrata y, en particular, su separación de la cesión ilegal de trabajadores. Las enmiendas n. 2 y n. ${ }^{\circ} 27$, quizás de manera poco sistemática, exigen que la empresa contratista o subcontratista cuente con estructura organizativa «adecuada a su objeto social», infraestructura de medios materiales y personales propia, y organización estable "que garantice una actividad propia» y poner al servicio de la ejecución de la contrata dicha organización y, en particular, «ejercer el poder de dirección». En la misma línea delimitadora, otras enmiendas con mejor criterio técnico prefieren plantear modificaciones al texto del art. $43 \mathrm{ET}$, como es el caso de la enmienda n. ${ }^{\circ}$ 12, presentada por Esquerra Republicana, o la n. ${ }^{\circ} 16$, presentada por el Grupo Parlamentario Mixto. Ambas hacen referencia a la exigencia de "autonomía técnica» de la contrata, aunque la segunda incluye exigencias adicionales relacionadas con la autonomía de la contrata, en sentido bastante próximo a los contenidos de las enmiendas presentadas por los Grupos Socialista y Unidos Podemos.

\subsection{Estabilidad en el empleo y transmisión de contratas y subcontratas}

Más allá de la eficacia de los mecanismos de garantía a los que se ha hecho referencia más arriba, en mi opinión, los elementos esenciales de la reforma en la materia, curiosamente, no formarían parte de la regulación contenida en el 
art. $42 \mathrm{ET}$, en la medida en que las previsiones que pueden garantizar un mayor nivel de estabilidad en el empleo a las personas que prestan servicio para contratas y subcontratas se encuentran hoy en día reguladas en los arts. 15.1.a) y 44.2 ET.

A la primera cuestión ya me he referido ampliamente en apartados precedentes, baste ahora con señalar que la exclusión de la posibilidad de hacer uso del contrato por obra o servicio determinado forma parte también de los textos de las enmiendas que se analizan, en mi opinión, con mayor alcance del que se desprende de la más reciente jurisprudencia. En concreto, la enmienda n. ${ }^{\circ} 10$, presentada por Unidos Podemos, propone modificar la letra a) del art. 15.1, para negar valor justificativo, a efectos de la celebración de un contrato de duración determinada, a los supuestos de "contratación y subcontratación de obras y servicios por parte de la empresa, ya sea de naturaleza civil, mercantil o administrativa». Por su parte, la enmienda n. ${ }^{\circ}$ 27, presentada por el Grupo Socialista, encomienda a la negociación colectiva sectorial o de empresa la posibilidad de establecer mecanismos de prevención del fraude en la contratación de duración determinada en este ámbito. En este punto, la siempre saludable intención de promocionar la negociación colectiva queda bastante fuera de lugar tras la lectura del fallo de la STS n. ${ }^{\circ}$ 4383/2020, de 29 de diciembre de 2020, rcud. 240/2018.

Con relación a la sucesión de contratas, la enmienda n. ${ }^{\circ}$ 9, presentada por Unidos Podemos, propone la adición de un nuevo apartado 11 al ya extenso art. $44 \mathrm{ET}$, por el que tanto la externalización inicial de actividades, como los eventuales cambios de titularidad de la contrata o subcontrata, y la reversión de la actividad a la empresa principal serían considerados supuestos de transmisión de empresa, a todos los efectos. Conviene tener presente que la referencia se limita a las contratas de propia actividad, por lo que prime facie, la reforma dejaría sin solucionar los cambios de contrata en los sectores más necesitados de atención, según se ha dicho con anterioridad. A mayor abundamiento, ni la normativa de la UE en la materia, ni la jurisprudencia del TJUE, ni el vigente art. 44 ET establecen diferencia alguna entre transmisión de empresas de propia o diferente actividad. Sin perjuicio de lo anterior, si junto a esta enmienda fuera aceptada la que redefine el concepto de propia actividad, presentada por el mismo grupo parlamentario, la cobertura del art. 44 et al.canzaría también a estos sectores especializados en la prestación de servicios complementarios para empresas.

Con el mismo objetivo, aunque con distinta técnica, la enmienda n. ${ }^{\circ} 13$, presentada por Esquerra Republicana, plantea la incorporación de un inciso adicional al contenido del apartado 2 del art. 44 ET, que define el concepto «entidad económica» que mantiene su identidad, para añadir los supuestos en los que la empresa entrante se hace cargo de "una parte esencial, en términos de número y de competencias, del personal de su antecesor destinaba especialmente a dicha tarea». La previsión traslada a la letra de la norma el sentido de la jurisprudencia conocida como "sucesión en la plantilla», tesis elaborada a partir del fallo de la 
STJUE de 24 de enero de 2002, asunto C-51/00. Más allá de positivar una doctrina jurisprudencial bastante asentada, la propuesta plantea la misma problemática sobre la que se ha reflexionado más arriba, con relación a la STJUE de 11 de julio de 2018, asunto C- 60/2017, en la medida en que contribuye a desincentivar la actividad negociadora en los convenios colectivos sectoriales de actividades complementarias. Por último, muy en la línea de otras enmiendas del Grupo Socialista, la n. ${ }^{\circ} 28$ deja en manos de la negociación colectiva la posibilidad de establecer los efectos en los distintos supuestos de cambio de contratista, posibilidad en nada vetada por la legislación vigente que, como es conocido, ni ha resuelto los problemas de aplicación en nuestro país de la normativa de la UE en la materia, ni ha conseguido alcanzar el grado de protección ofrecido por la norma legal.

\subsection{La reforma de la subcontratación como vía para reformar la negociación colectiva}

Aunque la Proposición de ley original pretendía la modificación de art. 42 ET con carácter exclusivo, como se ha visto, las enmiendas se extienden sobre materias relacionadas directamente con las contratas y subcontratas incluidas en otros preceptos legales. Adicionalmente, algunas otras enmiendas tienen por objeto la modificación de aspectos de alcance general de la regulación laboral, en particular los relacionados con la negociación colectiva, que pueden afectar tanto a las contratas y subcontratas, como al resto de las empresas, independientemente de su estructura organizativa.

En materia de prioridad aplicativa del convenio de empresa, la enmienda n. ${ }^{\circ} 14$, presentada por Esquerra Republicana, propone la eliminación del apartado 2 del art. $84 \mathrm{ET}$, precepto que establece la prioridad aplicativa de la regulación sobre las materias esenciales reguladas en los convenios colectivos de ámbito de empresa sobre los convenios colectivos sectoriales lo que, en la práctica, permite a estos establecer condiciones menos favorables a los intereses de los trabajadores, reduciendo el estándar sectorial. En apartados precedentes se ha señalado esta regulación como responsable, en parte, del auge de las empresas multiservicios y de la precarización de las condiciones de trabajo de quienes prestan servicio en contratas y subcontratas. La supresión del apartado significaría la reposición del régimen jurídico precedente a la reforma de 2012 en materia de estructuración de la negociación colectiva, sin remodelar algunos otros aspectos que, en mi opinión, también debieran ser retocados con el objetivo de mejorar una regulación, la relativa a la concurrencia de convenios colectivos, que ha sido tradicionalmente objeto de crítica doctrinal. En todo caso, por lo que respecta a las contratas y subcontratas, el cambio normativo favorecería la extensión del paraguas de protección sectorial a las empresas contratistas y subcontratistas que, durante estos casi diez años, han celebrado convenios propios a la baja. Sin embargo, ninguna de estas propuestas plantea introducir previsión alguna en torno a la determinación del convenio colectivo sectorial aplicable a las 
empresas multiservicios. Es cierto que el fallo de la STS n. ${ }^{\circ}$ 438/2020, de 11 de junio, rec. 1546/2016, se emite bastantes meses después del cierre del plazo de presentación de enmiendas, pero convendría tener en cuenta su sentido en una próxima reforma.

Por su parte, la enmienda n. ${ }^{\circ}$ 19, presentada por el Grupo Mixto, propone la modificación de la regulación de la legitimación para negociar convenios colectivos de empresa en el banco social. En concreto, se plantea el interés por establecer prioridad para negociar en dicho ámbito a las secciones sindicales y, en ausencia de estas, pero siempre con la autorización de la representación unitaria, a los sindicatos más representativos. La previsión resulta bastante novedosa y, aplicada con carácter general como se propone, supondría un cierto vuelco a la situación tradicional, caracterizada por el predominio de la representación unitaria. La revalorización del protagonismo de las secciones sindicales de empresa, en mi opinión, merece una reflexión más profunda y una regulación con mayor grado de integridad de la actividad de los delegados sindicales. En todo caso, la enmienda no aclara aspectos esenciales para la implementación de la propuesta como las mayorías necesarias para llegar a acuerdo, o la composición de la comisión negociadora. En este mismo apartado, merece la pena reseñar la enmienda n. ${ }^{\circ} 22$, presentada por Ciudadanos, que tiene también por objeto la modificación del art. 87.1 ET en sentido muy similar. La enmienda plantea legitimar con carácter prioritario a las secciones sindicales que agrupen a la mayoría de los miembros de la representación unitaria y, en ausencia de acuerdo mayoritario o de presencia de secciones sindicales, y previa delegación realizada por el comité de empresa o por los delegados de personal, a los sindicatos más representativos. Aunque esta propuesta mejora técnicamente la anterior, no se acierta a comprender el interés o la virtualidad de la reforma, en una materia en la que, con el régimen vigente, las secciones sindicales que gozan de mayoría en la representación unitaria no se encuentran con problema alguno para proceder a negociar un convenio colectivo de ámbito empresarial.

\section{Conclusiones}

El trabajo parlamentario realizado en la anterior legislatura propone soluciones para responder a la mayoría de los problemas advertidos por doctrina y jurisprudencia. Con toda seguridad, estas propuestas están siendo objeto de discusión en la mesa de diálogo social, proceso que debe cerrarse con un acuerdo en la materia, en beneficio del sistema de relaciones laborales considerado en su conjunto. En mi opinión, aunque la reforma no puede ignorar los efectos que sobre los procesos de descentralización productiva proyectan las normas de aplicación general, sería contraproducente aprovechar la transformación de la normativa sobre subcontratación para alterar las reglas generales relativas a la ne- 
gociación colectiva que, necesitadas también de reforma, merecen un espacio propio de discusión. En otras palabras, la reforma de la subcontratación debiera enfocarse desde la especificidad de la figura objeto de análisis y, por ello, los cambios, aunque sería indispensable que fueran más allá del contenido del art. $42 \mathrm{ET}$, no debieran afectar previsiones de carácter general.

El reequilibrio de las relaciones de trabajo en las contratas exige una reforma integral de la regulación vigente que desborde el sistema de aseguramiento de la satisfacción de las deudas salariales y de seguridad social para un número limitado de actividades. Los fines y funciones de la regulación deben ser redefinidos desde una perspectiva más actualizada, a partir de las experiencias negativas cosechadas durante los últimos decenios. En particular, la nueva regulación debe diseñarse con el objetivo de resolver la problemática planteada por las empresas multiservicios, mediante la introducción de mecanismos de dignificación de las condiciones de trabajo, de promoción de la actividad de las representaciones de los trabajadores en la empresa, y de garantía del efecto útil de regulación del ejercicio de las libertades sindicales. Si hasta la fecha, la regulación se despliega en torno al concepto de propia actividad, la experiencia aplicativa podría aconsejar un cambio radical, para conceder dicho protagonismo a otro tipo de elementos, como el dato locativo y la referencia temporal.

La reforma debe, en primer lugar, mejorar la sistemática del marco normativo vigente, mediante la adecuada conexión de las regulaciones en la materia contenidas en las normas laborales, de seguridad social y de prevención de riesgos laborales. Particular atención debe prestarse a la normativa específica del sector de la construcción, cuya continuidad debiera evaluarse a la luz del alcance de la futura regulación.

En la misma lógica, en segundo lugar, la regulación debiera eliminar viejos problemas interpretativos, en particular, la diferenciación entre contrata y cesión ilegal, la concatenación de responsabilidades entre contratistas y subcontratistas, la duplicidad de regímenes de protección en atención al tipo de actividad desarrollada, y la condición de «entidad económica que mantiene su identidad» de la contrata. En otras palabras, debe perseguirse y castigarse con mayor eficacia e intensidad la cesión de mano de obra, las responsabilidades por deudas deben recorrer toda la cadena de subcontratación, debe eliminarse el concepto propia actividad y el art. 44 ET debe aplicarse a todos los cambios en la titularidad de la contrata. La eliminación del concepto propia actividad podría compensarse con la introducción de un elemento temporal, lo que excluiría de la protección ofrecida por el art. 42 ET los supuestos de colaboraciones puntuales entre empresas. Adicionalmente, la articulación de un sistema gradual de protección, en torno al binomio protección básica versus protección reforzada, podría mantenerse, reservando la segunda de las fórmulas a los supuestos de contratas y subcontratas que se desarrollan en el centro de trabajo de la comitente. 
En tercer lugar, la renovada jurisprudencia en la materia soluciona parcialmente los problemas de abuso de la contratación temporal en el sector de las contratas de obras y servicios, aunque el legislador no debiera dejar en manos de los jueces toda la responsabilidad en este apartado. La expresa prohibición de utilización de la modalidad de contratación establecida en el art. 15.1.a) ET dotaría a las personas que prestan servicio por cuenta de contratas y subcontratas de la necesaria estabilidad.

En cuarto lugar, en los supuestos de prestación de servicios en el centro de trabajo de la comitente, la igualación de condiciones de trabajo vigentes en la empresa principal y, subsidiariamente, la aplicación del correspondiente convenio colectivo sectorial, podría resolver las cuestiones ligadas a la precarización de las condiciones de trabajo en empresas multiservicios. En el mismo ámbito, las lagunas derivadas de la insuficiencia del marco normativo sobre representación de los trabajadores podrían reducirse mediante una asunción plena de las facultades representativas por parte de los miembros de la representación unitaria de la principal, en ausencia de representación propia. Adicionalmente, las facultades de los delegados y delegadas sindicales podrían extenderse sobre las personas sindicadas que prestan servicio en el centro de trabajo de la comitente. Por último, cuando exista representación de las personas trabajadoras, los derechos de información y los medios de coordinación deben extenderse al conjunto de actividades objeto de contratación o subcontratación, independientemente del lugar en el que se presten los servicios.

En quinto lugar, la introducción de las modificaciones normativas más arriba enumeradas incrementaría los costes y, por consiguiente, desincentivaría el uso de prácticas de cesión ilegal, aunque la regulación podría completarse introduciendo el concepto de autonomía técnica entre los indicios delimitadores contenidos en el art. 43 ET.

Una reforma del marco normativo de la regulación laboral de las contratas y subcontratas, elaborada a partir de las anteriores premisas, debiera evitar reiteraciones expresas, fórmulas de protección redundantes y el incremento de las dudas interpretativas. De manera preventiva, se sugiere la reducción de la extensión de las futuras previsiones normativas, la simplificación de las fórmulas y mecanismos de garantía de derechos y el ajuste sistemático del futuro marco normativo en su globalidad.

\section{Bibliografía}

Cruz Villalón, Jesús (1992) «Descentralización productiva y responsabilidad laboral por contratas y subcontratas", Relaciones Laborales, n. ${ }^{\circ}$ 1, pp. 114-162.

Esteve Segarra, Amparo (2017) «Vías para atajar la precariedad en las empresas multiservicios. Una contribución al debate», Revista de Derecho Social, n. o 77, pp. 215-238.

Gómez Gordillo, Rafael (2010) «El impacto de los procesos de descentralización productiva sobre la eficacia de la norma laboral», en Cruz Villalón, Jesús (dir.), Eficacia de las normas laborales desde la perspectiva de la calidad en el empleo, Tirant lo Blanch, Valencia, 2010, pp. 110-163. 
Gómez Gordillo, Rafael (2017a) «La preferencia del convenio colectivo de empresa. Análisis de los límites materiales de aplicación de uno de los pilares de la reforma de 2012», en Cruz Villalón, Jesús (dir) La negociación colectiva como instrumento de gestión del cambio, Cinca, Madrid, pp. 53-75.

Gómez Gordillo, Rafael (2017b) «La propia actividad como límite a la propuesta de igualación de condiciones de trabajo en las cadenas de subcontratación: justificación y alternativas», en Cardona Rubert, María Belén (dir.), Cambio laboral y políticas inclusivas, Universitat de València, pp. 385-396.

Gómez Gordillo, Rafael (2018) «Funcionalidad del concepto propia actividad en la empresa descentralizada", Descentralización productiva, nuevas formas de trabajo y organización empresarial, AEDTSS, Cinca.

Gómez Gordillo, Rafael (2019) «La subrogación de contratas prevista en convenio colectivo", en Molina Navarrete, Cristóbal (coord.), Impacto sobre la legislación laboral española de la jurisprudencia del Tribunal de Justicia de la Unión Europea, CARL, Sevilla, pp. 459-473.

Nores Torres, Luís Enrique (2004) El trabajo en contratas: la noción de contrata de propia actividad, Tirant lo Blanch, Valencia.

Pérez de los Cobos Orinuel, Francisco (2020) «Las libertades económicas y la regulación laboral de la contratación y subcontratación de obras y servicios», Nueva revista española de derecho del trabajo, n. ${ }^{\circ} 229$, pp. 23-41.

Sanguineti Raymond, Wilfredo (2021) «Subcontratación de actividades productivas y estabilidad en el empleo: el replanteamiento del modelo», Trabajo y Derecho: nueva revista de actualidad y relaciones laborales, n. ${ }^{0} 75$.

Soriano Cortés, Dulce (2007) Las contratas en el derecho del trabajo y de la Seguridad Social, Mergablum, Sevilla.

Soriano Cortés, Dulce (2000) «El derecho de información de los representantes de los trabajadores en los supuestos de subcontratación", Temas Laborales, n. ${ }^{\circ}$ 56, pp. 121-138.

VV.AA. (2018) La negociación colectiva en las empresas multiservicios. Un balance critico. Fundación 1. ${ }^{\circ}$ Mayo, Francis Lefebvre, El derecho, Madrid. 